\title{
Title: Paediatric Abusive Head Trauma in the Emergency Department. A multicentre prospective cohort study
}

\section{Type of manuscript: Original Article}

\section{Authors:}

Franz E Babl MD ${ }^{\mathrm{a}, \mathrm{b}, \mathrm{c}}$, Helena Pfeiffer ${ }^{\mathrm{a}, \mathrm{b}}$, Patrick Kelly MBChB ${ }^{\mathrm{d}, \mathrm{e}}$, Stuart R Dalziel PhD ${ }^{\mathrm{d}, \mathrm{e}}$, Ed Oakley MBBS $^{\mathrm{a}, \mathrm{b}, \mathrm{c}}$, Meredith L Borland MBBS ${ }^{\mathrm{f}, \mathrm{g}}$, Amit Kochar MD ${ }^{\mathrm{h}}$, Sarah Dalton BMedi, John A. Cheek MBBS $^{\mathrm{a}, \mathrm{b}, \mathrm{j}}$, Yuri Gilhotra MBBS ${ }^{\mathrm{k}, \mathrm{l}}$, Jeremy Furyk MBBS ${ }^{\mathrm{m}}$, Mark D. Lyttle MBChB ${ }^{\mathrm{b}, \mathrm{n}, \mathrm{o}}$, Silvia Bressan $\mathrm{MD}, \mathrm{PhD}^{\mathrm{b}, \mathrm{p}}$, Susan Donath MA ${ }^{\mathrm{b}, \mathrm{c}}$, Stephen J.C. Hearps PGDipBiostat ${ }^{\mathrm{b}}$, Anne Smith MBBS ${ }^{\mathrm{b}, \mathrm{q}}$, Louise Crowe $^{\mathrm{b}} \mathrm{PhD}$ on behalf of the Paediatric Research in Emergency Departments International Collaborative (PREDICT)

\section{Affiliations:}

aRoyal Children's Hospital, Melbourne, Australia;

${ }^{\text {b} M u r d o c h ~ C h i l d r e n ' s ~ R e s e a r c h ~ I n s t i t u t e, ~ M e l b o u r n e, ~ A u s t r a l i a ; ~}$

'Department of Paediatrics, Faculty of Medicine, Dentistry and Health Sciences, University of Melbourne, Melbourne, Australia;

'Starship Children's Health, Auckland, New Zealand;

eUniversity of Auckland, Auckland, New Zealand;

fPrincess Margaret Hospital for Children, Perth, Australia;

gDivisions of Paediatrics and Emergency Medicine, School of Medicine, University of Western

Australia, Crawley, Australia;

'Women's \& Children's Hospital, Adelaide, Australia;

'The Children's Hospital at Westmead, Sydney, Australia;

${ }^{j}$ Monash Medical Centre, Melbourne, Australia;

k'Lady Cilento Children's Hospital, Brisbane

${ }^{1}$ Child Health Research Centre, School of Medicine, The University of Queensland, Brisbane,

Australia;

${ }^{m}$ The Townsville Hospital, Townsville, Australia;

"Bristol Royal Hospital for Children, Bristol, United Kingdom;

${ }^{\circ}$ Academic Department of Emergency Care, University of the West of England, Bristol, United Kingdom;

PDepartment of Women's and Children's Health, University of Padova, Padova, Italy;

qVictorian Forensic Paediatric Medical Service, Royal Children’s Hospital, Melbourne, Australia

\section{Corresponding Author:}

Franz E Babl,

Department of Emergency Medicine,

Royal Children's Hospital,

This is the author manuscript accepted for publication and has undergone full peer review but has not been through the copyediting, typesetting, pagination and proofreading process, which may lead to differences between this version and the Version of Record. Please cite this article as doi: $10.1111 /$ jpc.14700 
50 Flemington Road, Parkville 3052,

Australia

Email:_ franz.babl@rch.org.au

Phone: $\quad+61399366748$

Fax: $\quad+61393455938$

\section{FUNDING}

The study was funded by grants from the National Health and Medical Research Council (project grant GNT1046727, Centre of Research Excellence for Paediatric Emergency Medicine GNT1058560), Canberra, Australia; the Murdoch Childrens Research Institute, Melbourne, Australia; the Emergency Medicine Foundation (EMPJ-11162), Brisbane, Australia; Perpetual Philanthropic Services (2012/1140), Australia; Auckland Medical Research Foundation (No. 3112011) and the A + Trust (Auckland District Health Board), Auckland, New Zealand; WA Health Targeted Research Funds 2013, Perth, Australia; the Townsville Hospital and Health Service Private Practice Research and Education Trust Fund, Townsville, Australia; and supported by the Victorian Government's Infrastructure Support Program, Melbourne, Australia. FEB's time was part funded by a grant from the Royal Children’s Hospital Foundation and a Melbourne Children's Clinician Scientist Fellowship, Melbourne, Australia, and an NHMRC Practitioner Fellowship, Canberra, Australia. SRD's time was part funded by the Health Research Council of New Zealand (HRC13/556).

\section{Acknowledgement}

We would like to thank the participating families and emergency department staff at participating sites. We would like to thank research staff from the participating sites.

\section{Declaration of conflicts of interests}

None of the authors have conflicts of interests.

\section{ABSTRACT (250)}

Aim:

Abusive head trauma (AHT) is associated with high morbidity and mortality. We aimed to describe characteristics of cases where clinicians suspected AHT and confirmed AHT cases, and describe how they differed. 


\section{Methods:}

Planned secondary analysis of a prospective multicentre cohort study of head injured children aged $<18$ years across 5 centres in Australia and New Zealand. We identified cases of suspected AHT when emergency department (ED) clinicians raised suspicion on a clinical report form or based on research assistant assigned epidemiology codes. Cases were categorized as AHT positive, negative and indeterminate after multidisciplinary review. Suspected and confirmed AHT and non-AHT cases were compared using odds ratio (OR) with 95\% confidence intervals (CIs).

\section{Results:}

AHT was suspected in 70 of 13371 (0.5\%) head injured children. Out of these, 23 (32.9\%) were categorized AHT positive, 18 (25.7\%) AHT indeterminate and 29 (27.1\%) AHT negative. Median age was 0.8 years in suspected, 1.4 in confirmed AHT and 4.1 in non-AHT cases. ORs (95\% CI) for presenting features and outcomes in confirmed AHT vs. non AHT were: loss of consciousness 2.8 (1.2-6.9), scalp haematoma 3.9 (1.7-9.0), seizures 12.0 (4.035.5), Glasgow coma scale (GCS) $\leq 1230.3$ (11.8-78.0), abnormal neuroimaging 38.3 (16.887.5), intensive care admission 53.4 (21.6-132.5) and mortality 105.5 (22.2-500.4).

\section{Conclusions:}

ED presentations of children with suspected and confirmed AHT had higher rates of loss of consciousness, scalp haematomas, seizures and low GCS. These cases were at increased risk of abnormal computed tomography scans, need for intensive care and death.

Key words: abusive head trauma, head injury, infant, child, child abuse 


\section{What is already known on this topic}

- Abusive head trauma in children has high morbidity and mortality.

- Abusive head trauma is difficult to identify in the emergency department.

\section{What this paper adds}

- Clinicians rarely suspected abusive head trauma in a large multicentre emergency department data set of head injuries of any severity.

- Emergency presentations of abusive head trauma had higher rates of loss of consciousness, scalp haematoma, seizures and low Glasgow Coma Scale scores.

- These injuries had an increased risk of abnormal computed tomography of the head, neurosurgery and death. 


\section{Introduction}

Abusive head trauma (AHT) is the main cause of traumatic death in children under one year of age and is the leading cause of death due to child abuse. [1] Outcome studies have shown an overall mortality of 20\%, with high levels of subsequent disability in survivors [2] including vision and hearing impairments, epilepsy, cerebral palsy, and developmental and cognitive delay. [3]

While the incidence of AHT is estimated to be between 33.4 and 38.8 per 100,000 children $<1$ year in the USA [4] and 33.8 per 100,000 infants per year in parts of the UK, [5] there is less information on AHT in Australasia. In New Zealand, 20 years of referrals to a hospital child protection team and national studies indicated an incidence of 34 per 100000 children $<2$ years. [6, 7] Emergency department (ED) based data from a single Australian centre reported $0.7 \%$ of head injuries in $<2$ year olds to have been inflicted by a parent. [8]

Given the high morbidity and mortality of AHT, early detection in the ED is paramount. It may, however, be difficult for clinicians to decide which head-injured children require further evaluation for abuse, as histories provided by caregivers in AHT cases may be misleading, [9] clinical features may be similar in accidental and inflicted head injuries and non-specific symptoms of brain injuries may be mistaken for medical diagnoses. [10] For these reasons, up to one third of victims of AHT are missed by physicians at first medical contact. [10]

There is likely scope for improvement in identifying children with AHT in Australian and New Zealand EDs. We need to understand what it currently is that clinicians take into account when arriving at that conclusion in terms of demographics, presentation and severity and how that correlates with the final diagnosis. Therefore we set out to describe the 
presenting features, acute clinical outcomes and final AHT status after multidisciplinary review of children where clinicians suspected AHT in a large multicentre Australasian ED dataset and compare them to cases, in which AHT was not suspected.

\section{Materials and methods}

\section{Study design, setting and patients}

We performed a planned secondary analysis of children with suspected AHT enrolled in a prospective multi-centre observational study performed in 10 paediatric EDs in Australia and New Zealand between April 2011 and November 2014. [11, 12] All EDs are members of the Paediatric Research in Emergency Departments International Collaborative (PREDICT) research network. [13]

For the primary study we collected and analysed predictor and outcome variables for three head injury clinical decision rules (CDRs) for neuroimaging [14-16] in all head injured children aged $<18$ years. [11, 12]. The study was registered with the Australian New Zealand Clinical Trials Registry (ANZCTR) ACTRN12614000463673.

Ethics approval was obtained from 5 participating sites for additional review of medical records of cases with possible AHT.

\section{Study procedures}

Details of the study protocol are described in detail elsewhere. [11, 12] In short, patients were enrolled by the treating ED clinician who collected clinical data. A research assistant (RA) recorded ED and hospital management data after the visit and conducted telephone follow-up for patients who had not undergone neuroimaging. In addition to data related to CDRs we collected demographic and epidemiological information as well as information about neuroimaging, admission and neurosurgery.

To identify possible cases of AHT among our population, we searched the study database for answers to relevant questions contained in the case report forms (CRF). While the patient was in the ED clinicians were asked on the clinical CRF prior to imaging "Do you suspect non- 
accidental injury (Physical abuse of a child, not other assault)?” Human intent codes were recorded by the RA after medical record review, and we reviewed all those with a human intent code other than non-intentional. In addition to extracting data from the study database we manually reviewed CRFs, case summaries developed by the RAs and the radiology reports for additional information. We then accessed medical records of possible AHT cases to determine the outcome as decided by a multidisciplinary team decision.

\section{Definitions}

We used the Glasgow Coma Scale (GCS) assigned by the ED clinician or if not available, GCS at triage. [17]

We used senior radiologist reports to determine the results of CT scans, and operative reports for patients who underwent neurosurgery.

Abnormal CT demonstrating a traumatic brain injury (TBI) was defined as intracranial haemorrhage or contusion, cerebral oedema, traumatic infarction, diffuse axonal injury, shearing injury, sigmoid sinus thrombosis, midline shift of intracranial contents or signs of brain herniation, diastasis of the skull, pneumocephalus or skull fracture depressed by the width of table of the skull. [14] In addition we included as abnormal CT any kind of skull fracture (depressed, non-depressed, basal, unknown type).

Neurosurgical intervention was defined as intracranial pressure monitoring, elevation of depressed skull fracture, ventriculostomy, haematoma evacuation, lobectomy, tissue debridement or dura repair.

Clinically-important traumatic brain injury (ciTBI) was defined as death from TBI, neurosurgical intervention for TBI, intubation of more than $24 \mathrm{~h}$ for TBI or hospital admission of 2 nights or more for TBI in association with TBI on CT. [14]

We used epidemiology codes based on Victorian government codes [18] that included activity, place, mechanism of injury and human intent. These were assigned by RAs at each site based on information recorded by the ED clinician, medical record review and follow-up telephone calls. 
Suspected AHT was defined as head injury which the treating clinician felt was suspected to be due to physical child abuse by parents or caregivers or where this was investigated.

AHT was defined as the diagnosis of cranial or intracranial head injury (confirmed on neuroimaging), which was due to physical child abuse by parents or caregivers, rather than neglect, according to the decision of a multidisciplinary child protection team at the conclusion of their investigation and their consideration of the relevant social, forensic and clinical features in the context of the presenting history in accordance with the Australian and New Zealand standard child protection assessment processes. Non-AHT was defined as witnessed accidental injury or accidental injury confirmed by the decision of a multidisciplinary child protection team. Cases were categorized as AHT positive or negative (non-AHT) by the study investigators upon review of the multidisciplinary team records. Cases in which this categorization was not clear were deemed indeterminate. [19] Any uncertainty in terms of category assignment on review of the records was arbitrated by the director of the Victorian Forensic Paediatric Medical Service (AS) based on the forensic reports and medical records.

Non-AHT was defined as cases, in which AHT was not suspected or investigated by the treating clinician.

\section{Statistical analysis}

Data were entered into Epidata (The Epidata Association, Odense, Denmark), and later REDCap, [20] and analysed using Stata 13 (Statacorp, College Station, Texas, USA). Descriptive statistics were calculated with 95\% confidence intervals (95\%CI) where relevant. In addition we calculated odds ratios (OR) with 95\% CI comparing presentation factors and outcome in suspected and confirmed AHT cases compared to non-AHT cases.

\section{Results}

This article is protected by copyright. All rights reserved. 
Of 13,371 head injury cases, we investigated 533 for further consideration because either the ED clinician had indicated a suspicion of AHT or the RA assigned a human intent code other than non-intentional on the CRFs (Figure 1). After review of CRFs, case summaries developed by the RAs and the radiology reports we excluded non-intentional head injuries as well as intentional head injuries inflicted by a person other than the caregiver (e.g. sibling, peer, stranger). Ultimately AHT was suspected and/or investigated in 70 cases $(0.5 \%$ of total cohort and 13.1\% of cohort reviewed). Out of these, 23 (32.9\%) were categorized AHT positive, 18 (25.7\%) AHT indeterminate and 29 (27.1\%) AHT negative by a multidisciplinary child protection team (Figure 1).

\section{Insert Figure 1}

Median age of suspected AHT cases was 0.7 years (IQR 0.2-1.9), of confirmed AHT 1.4 (0.4-6.8) and of not AHT suspected 4.1 (1.9-8.9) . Although much less common in older children, cases of suspected and confirmed AHT were seen in all age groups (Figure 2).

\section{Insert Figure 2}

Significant presenting clinical features in cases of confirmed AHT compared to non-AHT were loss of consciousness (OR = 2.8 (95\% CI 1.2-6.9), scalp haematoma (OR = 3.9 (95\% CI 1.7-9.0), seizures (OR = 12.0 (95\% CI 4.0-35.5) or GCS $\leq 1230.3$ (11.8-78.0) (Table 1 and

2). The other clinical variables did not differ significantly between groups.

\section{Insert Table 1 and 2}

In cases of suspected and confirmed AHT the most common mechanism recorded was "no specific mechanism” (57.1 and 82.7\%), followed by falls (38.6 and 13.0\%) and impact by object or projectile (2.9\% and $4.3 \%$ ) (Table 1).

This article is protected by copyright. All rights reserved. 
CT was performed in $65.7 \%$ of suspected AHT, of which $63.0 \%$ were abnormal, while clinicians deemed CT necessary in only 9.1\% of not AHT suspected head injury cases of which only 30.4\% were abnormal. In confirmed AHT cases, $63.2 \%$ of performed CTs were abnormal (OR=38.3 (16.8-87.5) The abnormal neuroimaging findings in suspected vs. confirmed AHT cases were most commonly skull fractures (73\% vs. 41.7.\%) or intracranial haemorrhage (65.4\% vs. 91.7\%). Skull fractures were non-depressed in 50.0\% and $19.2 \%$ were depressed in suspected AHT cases (Table 3).

\section{Insert Table 3}

Suspected AHT cases were more likely to be admitted (OR=16.9 (9.6-29.5) and undergo neurosurgery (OR=7.5, (1.8 - 31.4). Neurosurgical procedures in this group were craniotomy, haematoma evacuation and monitoring of intracranial pressure (Table 1). Suspected AHT cases were more likely to suffer from ciTBI $(\mathrm{OR}=19.0,(10.4-34.7)$ and were more likely to die $(\mathrm{OR}=32.6(10.4-34.7)$ as a result of their head injury. Two confirmed AHT cases $<2$ years who both presented with GCS 3 and multiple CT abnormalities died (Table 1).

\section{Discussion}

In this multicentre ED based study we identified 70 children where clinicians suspected AHT, out of which 23 were confirmed to have suffered AHT by a multidisciplinary team When comparing cases where AHT was suspected and confirmed with cases where it was not we found that suspected and confirmed AHT cases had higher rates of loss of consciousness, seizures and scalp haematomas. About two in three children with suspected AHT had a cranial CT and $63 \%$ of those were abnormal, while CT was less frequently ordered in nonAHT cases and less than a third of those were abnormal. Suspected and confirmed AHT cases had a much higher risk of presenting clinically unwell on arrival with a significantly higher risk of presenting with seizures and with low GCS, features which according to Jenny et al 
greatly increased the chance for AHT cases of not being missed. [10] The increased risk of seizures is consistent with Bennett's finding, that the triad of young age, injury by abuse and subdural haemorrhage poses the greatest risk of posttraumatic seizures in children with severe traumatic brain injury and also with the strong association of AHT with seizures in systematic reviews. [21-23] Consistent with the more severe presenting signs and symptoms, children with suspected and confirmed AHT have higher rates of ciTBI and mortality than non-AHT cases. This is in keeping with international literature in which AHT is associated with a higher rate of intracranial injuries and deaths. [6, 22]

This study confirms AHT to be associated with high morbidity and mortality.

Previous literature has usually focused on inpatient or intensive care based samples of AHT. [25, 26] ED based reports have mainly focused on demographics, such as health insurance and cost rather than clinical presentation. [27, 28] Clinical decision rules have been developed to determine children at increased risk of AHT [29, 30]; while Berger validated an ED based prediction rule, it did not provide a comparison between AHT and non-AHT cases in terms of presentation. [31]

As expected most children with suspected and confirmed AHT were infants and toddlers. [27, 32] We also identified older children with suspected AHT, i.e. caregiver inflicted head injuries. Formal definitions of AHT, such as the Centers for Disease Control and Prevention's AHT definition of "injury to the skull or intracranial contents of an infant or young child ( $<5$ years) due to inflicted blunt impact and/or violent shaking” [33] and most clinical prediction rules for AHT (confined to children aged $<2$ or $<3$ years) [25, 26] have restricted paediatric AHT to only young children. However, a study of 20 years of child protection referrals in Auckland, New Zealand, which included children up to the age of 15 years, found that mortality was even higher in older children with AHT presumably because of high impact mechanisms. [6]

In 57\% of suspected and $83 \%$ of confirmed AHT cases, a specific mechanism of injury was not noted. This is consistent with past reports indicating that parental history in these cases is 
often inconsistent or inadequate, the injury was unwitnessed or head trauma is denied. [6, 9, 34] As has been reported previously a history of trauma was missing in $69.4 \%$ of AHT cases vs. $2.6 \%$ in non-AHT cases. [9]

About one third of suspected AHT cases was ultimately confirmed to be AHT positive. As AHT could neither be confirmed or excluded in an additional $26 \%$ of cases, clinicians should have a low threshold in suspecting AHT in critically ill children with head injuries in the ED, as missing the diagnosis an have grave consequences for these children. [10]

\section{Limitations}

This study has a number of limitations. We were not able to determine if non-AHT cases where the intent code was assigned as non-intentional could have been misclassified by clinical staff and RAs and may actually be cases of AHT. Patients were followed up to three months after the presentation with a telephone call if no CT was undertaken and clinical records at the treating hospital (usually the neurosurgical and forensic referral centre) were reviewed again at the time of the follow-up call. However, this does not exclude the possibility that cases of AHT were missed.

Our data collection focused necessarily on history and clinical findings rather than providing details on parent interaction, history of domestic violence or prior involvement with child protection services.

The study focuses on ED presentations with head injuries diagnosed at the point of ED assessment. Cases that were not suspected in ED but may have been diagnosed later on the ward (such as those with non-specific symptoms like lethargy, poor feeding or vomiting with no external evidence of head injury) were not included in our sample. [31]

\section{Conclusions}

This article is protected by copyright. All rights reserved. 
Despite these limitations our study provides useful information on the clinical features that are associated with suspected and confirmed AHT in the ED which include loss of consciousness, low GCS, seizures, and scalp haematomas. Such cases are at high risk of abnormal CT scans, ciTBI and death. Our data would be consistent with previous studies that cases of AHT without these presenting features may be more likely to be missed by ED clinicians 


\section{Abbreviations}

AHT $=$ Abusive head trauma

$\mathrm{CI}=$ confidence interval

ciTBI = clinically important traumatic brain injury

$\mathrm{CRF}=$ clinical report form

$\mathrm{CT}=$ computed tomography

$\mathrm{ED}=$ emergency department

GCS = Glasgow coma scale

$\mathrm{OR}=$ odds ratio 


\section{REFERENCES}

[1] Duhaime AC, Christian CW, Rorke LR, Zimmerman RA. Nonaccidental head trauma in infants the "Shaken baby syndrome". N Engl J Med. 1999; 338: 1822-1829.

[2] Royal College of Radiologists, Royal College of Paediatrics and Child Health. Standards for Radiological Investigations of Suspected Non-accidental Injury. In: Health RCoPaC, ed., 2008.

[3] Christian CW, Committee on Child Abuse Neglect, American Academy of Pediatrics. The evaluation of suspected child physical abuse. Pediatrics. 2015; 135: e1337-1354.

[4] Shanahan ME, Zolotor AJ, Parrish JW, Barr RG, Runyan DK. National, regional, and state abusive head trauma: application of the CDC algorithm. Pediatrics. 2013; 132: e1546-1553.

[5] Minns RA, Jones PA, Mok JY. Incidence and demography of non-accidental head injury in southeast Scotland from a national database. Am J Prev Med. 2008; 34: S126-133.

[6] Kelly P, John S, Vincent AL, Reed P. Abusive head trauma and accidental head injury: a 20year comparative study of referrals to a hospital child protection team. Archives of disease in childhood. 2015; 100: 1123-1130.

[7] Kelly P, Farrant B. Shaken baby syndrome in New Zealand, 2000-2002. J Paediatr Child Health. 2008; 44: 99-107.

[8] Crowe L, Babl F, Anderson V, Catroppa C. The epidemiology of paediatric head injuries: data from a referral centre in Victoria, Australia. J Paediatr Child Health. 2009; 45: 346-350.

[9] Hettler J, Greenes DS. Can the initial history predict whether a child with a head injury has been abused? Pediatrics. 2003; 111: 602-607.

[10] Jenny C, Hymel KP, Ritzen A, Reinert SE, Hay TC. Analysis of missed cases of abusive head trauma. Jama. 1999; 281: 621-626.

[11] Babl FE, Borland ML, Phillips N, et al. Accuracy of PECARN, CATCH, and CHALICE head injury decision rules in children: a prospective cohort study. Lancet. 2017.

[12] Babl FE, Lyttle MD, Bressan S, et al. A prospective observational study to assess the diagnostic accuracy of clinical decision rules for children presenting to emergency departments after head injuries (protocol): the Australasian Paediatric Head Injury Rules Study (APHIRST). BMC Pediatr. 2014; 14: 148.

[13] Babl F, Borland M, Ngo P, et al. Paediatric Research in Emergency Departments International Collaborative (PREDICT): first steps towards the development of an Australian and New Zealand research network. Emerg Med Australas. 2006; 18: 143-147.

[14] Kuppermann N, Holmes JF, Dayan PS, et al. Identification of children at very low risk of clinically-important brain injuries after head trauma: a prospective cohort study. Lancet. 2009; 374: 1160-1170.

[15] Osmond MH, Klassen TP, Wells GA, et al. CATCH: a clinical decision rule for the use of computed tomography in children with minor head injury. CMAJ. 2010; 182: 341-348.

[16] Dunning J, Daly JP, Lomas JP, et al. Derivation of the children's head injury algorithm for the prediction of important clinical events decision rule for head injury in children. Archives of disease in childhood. 2006; 91: 885-891.

[17] Teasdale G, Jennett B. Assessment of coma and impaired consciousness. A practical scale. Lancet. 1974; 2: 81-84.

[18] Victorian Emergency Minimum Dataset (VEMD) User Manual. In: The Department of Health and Human Services, ed., Victoria 2016.

This article is protected by copyright. All rights reserved. 
[19] Rebecca T. Leeb LJP, Cindi Melanson, Thomas R. Simon, Ileana Arias. Child Maltreatment Surveillance: Uniform Definitions for Public Health and Recommended Data Elements. In: Prevention CfDCa, ed., Atlanta, Georgia, 2008.

[20] Harris PA, Taylor R, Thielke R, Payne J, Gonzalez N, Conde JG. Research electronic data capture (REDCap)--a metadata-driven methodology and workflow process for providing translational research informatics support. J Biomed Inform. 2009; 42: 377-381.

[21] Maguire JL, Kulik DM, Laupacis A, Kuppermann N, Uleryk EM, Parkin PC. Clinical prediction rules for children: a systematic review. Pediatrics. 2011; 128: e666-677.

[22] Piteau SJ, Ward MG, Barrowman NJ, Plint AC. Clinical and radiographic characteristics associated with abusive and nonabusive head trauma: a systematic review. Pediatrics. 2012; 130: 315-323.

[23] Bennett KS, DeWitt PE, Harlaar N, Bennett TD. Seizures in Children With Severe Traumatic Brain Injury. Pediatric critical care medicine : a journal of the Society of Critical Care Medicine and the World Federation of Pediatric Intensive and Critical Care Societies. 2017; 18: 54-63.

[24] Vinchon M, de Foort-Dhellemmes S, Desurmont M, Delestret I. Confessed abuse versus witnessed accidents in infants: comparison of clinical, radiological, and ophthalmological data in corroborated cases. Childs Nerv Syst. 2010; 26: 637-645.

[25] Hymel KP, Armijo-Garcia V, Foster R, et al. Validation of a clinical prediction rule for pediatric abusive head trauma. Pediatrics. 2014; 134: e1537-1544.

[26] Cowley LE, Morris CB, Maguire SA, Farewell DM, Kemp AM. Validation of a Prediction Tool for Abusive Head Trauma. Pediatrics. 2015; 136: 290-298.

[27] Xiang J, Shi J, Wheeler KK, Yeates KO, Taylor HG, Smith GA. Paediatric patients with abusive head trauma treated in US Emergency Departments, 2006-2009. Brain injury. 2013; 27: 1555-1561.

[28] Peterson C, Xu L, Florence C, et al. The medical cost of abusive head trauma in the United States. Pediatrics. 2014; 134: 91-99.

[29] Pfeiffer H, Crowe L, Kemp AM, et al. Clinical prediction rules for abusive head trauma: a systematic review. Archives of disease in childhood. 2018.

[30] Pfeiffer H, Smith A, Kemp AM, et al. External Validation of the PediBIRN Clinical Prediction Rule for Abusive Head Trauma. Pediatrics. 2018; 141.

[31] Berger RP, Fromkin J, Herman B, et al. Validation of the Pittsburgh Infant Brain Injury Score for Abusive Head Trauma. Pediatrics. 2016.

[32] Niederkrotenthaler T, Xu L, Parks SE, Sugerman DE. Descriptive factors of abusive head trauma in young children--United States, 2000-2009. Child Abuse Negl. 2013; 37: 446-455.

[33] Parks SE AJ, Hill HA, Karch DL. Pediatric Abusive Head Trauma: Recommended Definitions for Public Health Surveillance and Research. In: Centers for Disease Control and Prevention, ed., Atlanta (GA), 2012.

[34] Amagasa S, Matsui H, Tsuji S, Moriya T, Kinoshita K. Accuracy of the history of injury obtained from the caregiver in infantile head trauma. Am J Emerg Med. 2016; 34: 1863-1867.

This article is protected by copyright. All rights reserved. 
This article is protected by copyright. All rights reserved. 
Table 1: Demographics, mechanism of injury, symptoms and signs, management and outcome

\begin{tabular}{|c|c|c|c|c|c|c|c|c|c|c|c|c|}
\hline \multirow[b]{2}{*}{ Characteristic } & \multicolumn{2}{|r|}{ Total } & \multicolumn{2}{|c|}{ AHT not suspected } & \multicolumn{2}{|c|}{$\begin{array}{l}\text { AHT suspected } \\
\text { (Total) }\end{array}$} & \multicolumn{2}{|c|}{ AHT positive } & \multicolumn{2}{|c|}{$\begin{array}{c}\text { AHT } \\
\text { indeterminate }\end{array}$} & \multicolumn{2}{|c|}{ AHT negative } \\
\hline & $\mathrm{n}$ & (\%) & $\mathrm{n}$ & (\%) & $\mathrm{n}$ & (\%) & $\mathrm{n}$ & (\%) & $\mathrm{n}$ & (\%) & $\mathrm{n}$ & $(\%)$ \\
\hline $\mathrm{N}$ & 13371 & & 13301 & & 70 & & 23 & & 18 & & 29 & \\
\hline Mean age [years] (SD) & 5.67 & $(4.61)$ & 5.69 & $(4.60)$ & 2.25 & (3.76) & 4.17 & $(5.46)$ & 1.49 & $(2.65)$ & 1.19 & (1.63) \\
\hline $\begin{array}{l}\text { Median age [years] } \\
\text { (IQR) }\end{array}$ & 4.12 & $(1.89-8.86)$ & 4.14 & $(1.91-8.88)$ & 0.72 & $(0.24-1.91)$ & 1.40 & $(0.42-6.77)$ & 0.65 & $(0.23-1.36)$ & 0.72 & $(0.25-1.64)$ \\
\hline Aged $<2$ yrs & 3558 & (26.61) & 3505 & (26.35) & 53 & $(75.71)$ & 13 & $(56.52)$ & 15 & (83.33) & 25 & (86.21) \\
\hline Female & 4838 & (36.18) & 4807 & (36.14) & 31 & (44.29) & 8 & (34.78) & 10 & (55.56) & 13 & (44.83) \\
\hline $\begin{array}{l}\text { Known or suspected } \\
\text { LOC }\end{array}$ & 1813 & (13.56) & 1801 & (13.54) & 12 & $(17.14)$ & 7 & (30.43) & 3 & (16.67) & 2 & (6.90) \\
\hline History of vomiting & 2305 & (17.24) & 2286 & (17.19) & 19 & (27.14) & 6 & (26.09) & 6 & (33.33) & 7 & (24.14) \\
\hline Fall related & 9413 & $(70.40)$ & 9386 & (70.57) & 27 & (38.57) & 3 & (13.04) & 6 & (33.33) & 18 & $(62.07)$ \\
\hline Motor vehicle incident & 555 & $(4.15)$ & 554 & $(4.17)$ & 1 & $(1.43)$ & 0 & $(0.00)$ & 0 & $(0.00)$ & 1 & $(3.45)$ \\
\hline $\begin{array}{l}\text { Head hit by high impact } \\
\text { object/projectile } \\
\text { GCS }\end{array}$ & 827 & (6.19) & 825 & $(6.20)$ & 2 & $(2.86)$ & 1 & $(4.35)$ & 0 & $(0.00)$ & 1 & $(3.45)$ \\
\hline $3-8$ & 82 & $(0.61)$ & 79 & $(0.59)$ & 3 & (4.29) & 3 & $(13.04)$ & 0 & $(0.00)$ & 0 & $(0.00)$ \\
\hline $9-12$ & 78 & $(0.58)$ & 74 & $(0.56)$ & 4 & (5.71) & 3 & (13.04) & 1 & (5.56) & 0 & $(0.00)$ \\
\hline 13 & 102 & $(0.76)$ & 101 & $(0.76)$ & 1 & (1.43) & 0 & $(0.00)$ & 1 & (5.56) & 0 & $(0.00)$ \\
\hline 14 & 425 & (3.18) & 418 & $(3.14)$ & 7 & (10.00) & 4 & (17.39) & 3 & (16.67) & 0 & $(0.00)$ \\
\hline 15 & 12528 & (93.70) & 12474 & (93.78) & 54 & (77.14) & 13 & (56.52) & 13 & (72.22) & 28 & (96.55) \\
\hline $\mathrm{GCS} \leq 8$ & 82 & $(0.61)$ & 79 & $(0.59)$ & 3 & $(4.29)$ & 3 & (13.04) & 0 & $(0.00)$ & 0 & $(0.00)$ \\
\hline GCS $\leq 12$ & 160 & $(1.20)$ & 153 & (1.15) & 7 & (10.00) & 6 & (26.09) & 1 & (5.56) & 0 & $(0.00)$ \\
\hline Scalp haematoma & 3838 & (28.70) & 3792 & (28.51) & 46 & (65.71) & 14 & (60.87) & 13 & (72.22) & 19 & (65.52) \\
\hline Seizure & 240 & $(1.79)$ & 230 & $(1.73)$ & 10 & (14.29) & 4 & (17.39) & 2 & (11.11) & 4 & (13.79) \\
\hline Cranial CT & 1258 & $(9.41)$ & 1212 & (9.11) & 46 & (65.71) & 19 & (82.61) & 11 & (61.11) & 16 & (55.17) \\
\hline
\end{tabular}

This article is protected by copyright. All rights reserved. 


\begin{tabular}{|c|c|c|c|c|c|c|c|c|c|c|c|c|}
\hline $\begin{array}{l}\text { Abnormal } \\
\text { neuroimaging }\end{array}$ & 397 & $(2.97)$ & 368 & $(2.77)$ & 29 & $(41.43)$ & 12 & $(52.17)$ & 5 & $(27.78)$ & 12 & (41.38) \\
\hline $\begin{array}{l}\text { Intra-cranial } \\
\text { haemorrhage/contusion }\end{array}$ & 212 & (1.59) & 194 & $(1.46)$ & 18 & $(25.71)$ & 11 & $(47.83)$ & 4 & $(22.22)$ & 3 & (10.34) \\
\hline Skull fracture & 295 & $(2.21)$ & 274 & $(2.06)$ & 21 & $(30.00)$ & 5 & $(21.74)$ & 4 & $(22.22)$ & 12 & (41.38) \\
\hline Neurosurgery & 54 & $(0.40)$ & 52 & $(0.39)$ & 2 & $(2.86)$ & 1 & $(4.35)$ & 0 & $(0.00)$ & 1 & $(3.45)$ \\
\hline Intubation & 113 & $(0.85)$ & 107 & $(0.80)$ & 6 & (8.57) & 6 & $(26.09)$ & 0 & $(0.00)$ & 0 & $(0.00)$ \\
\hline Admission & 2272 & (16.99) & 2218 & (16.68) & 54 & $(77.14)$ & 18 & (78.26) & 14 & (77.78) & 22 & (75.86) \\
\hline $\begin{array}{l}\text { Median length of stay } \\
\text { [days] (IQR) }\end{array}$ & 1 & $(1-1)$ & 3 & $(2-4)$ & 1 & $(1-1)$ & 4 & $(2-7)$ & 2 & $(2-3)$ & 2 & $(2-3)$ \\
\hline PICU Admission & 116 & $(0.87)$ & 108 & $(0.81)$ & 8 & (11.43) & 7 & $(30.43)$ & 0 & $(0.00)$ & 1 & $(3.45)$ \\
\hline ciTBI & 187 & $(1.40)$ & 173 & $(1.30)$ & 14 & $(20.00)$ & 10 & $(43.48)$ & 3 & $(16.67)$ & 1 & $(3.45)$ \\
\hline Mortality & 14 & $(0.10)$ & 12 & $(0.09)$ & 2 & $(2.86)$ & 2 & $(8.70)$ & 0 & $(0.00)$ & 0 & $(0.00)$ \\
\hline
\end{tabular}


Table 2: Odds Ratios comparing suspected abusive head trauma (AHT) (n=70) and confirmed AHT positive cases (23) to cases where AHT was not suspected $(\mathrm{n}=13,301)$.

\begin{tabular}{|c|c|c|c|c|c|c|c|c|c|c|c|}
\hline \multirow[b]{2}{*}{ Characteristic } & \multicolumn{2}{|c|}{$\begin{array}{l}\text { AHT suspected } \\
\text { (Total) }\end{array}$} & \multicolumn{2}{|c|}{ AHT not suspected } & \multirow[b]{2}{*}{ OR } & & \multicolumn{2}{|c|}{ AHT positive } & \multicolumn{3}{|c|}{ (vs. AHT not suspected) } \\
\hline & $\mathrm{n}$ & $(\%)$ & $\mathrm{n}$ & $(\%)$ & & $95 \% \mathrm{CI}$ & $\mathrm{n}$ & $(\%)$ & OR & & $5 \%$ CI \\
\hline $\mathrm{N}$ & 70 & & 13301 & & & & 23 & & & & \\
\hline Mean age [years] (SD) & 2.25 & (3.76) & 5.69 & $(4.60)$ & & & 4.17 & $(5.46)$ & & & \\
\hline Median age [years] (IQR) & 0.72 & $(0.24-1.91)$ & 4.14 & $(1.91-8.88)$ & & & 1.40 & $(0.42-6.77)$ & & & \\
\hline Aged $<2$ yrs & 53 & $(75.71)$ & 3505 & $(26.35)$ & 8.71 & (5.04 -15.07) & 13 & $(56.52)$ & 3.63 & $(1.59$ & $-8.29)$ \\
\hline Female & 31 & (44.29) & 4807 & (36.14) & 1.40 & $(0.88-2.25)$ & 8 & (34.78) & 0.94 & $(0.40$ & $-2.22)$ \\
\hline Known or suspected LOC & 12 & (17.14) & 1801 & (13.54) & 1.32 & $\left(\begin{array}{ll}0.71 & -2.46\end{array}\right)$ & 7 & (30.43) & 2.79 & (1.15 & $-6.80)$ \\
\hline History of vomiting & 19 & $(27.14)$ & 2286 & (17.19) & 1.80 & $\left(\begin{array}{ll}1.06 & -3.05\end{array}\right)$ & 6 & (26.09) & 1.70 & $(0.67$ & $-4.32)$ \\
\hline Fall related & 27 & $(38.57)$ & 9386 & (70.57) & 0.26 & $\left(\begin{array}{ll}0.16 & -0.42\end{array}\right)$ & 3 & (13.04) & 0.06 & $(0.02$ & $-0.21)$ \\
\hline Motor vehicle incident & 1 & $(1.43)$ & 554 & $(4.17)$ & 0.33 & $(0.05-2.41)$ & 0 & $(0.00)$ & & & \\
\hline $\begin{array}{l}\text { Head hit by high impact } \\
\text { object/projectile }\end{array}$ & 2 & $(2.86)$ & 825 & $(6.20)$ & 0.44 & $(0.11-1.82)$ & 1 & $(4.35)$ & 0.69 & $(0.09$ & $-5.11)$ \\
\hline GCS & & & & & & & & & & & \\
\hline 3-8 & 3 & $(4.29)$ & 79 & $(0.59)$ & 7.49 & (2.31 -24.33) & 3 & (13.04) & 25.11 & (7.31 & $-86.19)$ \\
\hline $9-12$ & 4 & (5.71) & 74 & $(0.56)$ & 10.83 & (3.85 -30.49$)$ & 3 & (13.04) & 26.81 & (7.80 & $-92.17)$ \\
\hline 13 & 1 & $(1.43)$ & 101 & $(0.76)$ & 1.89 & $\left(\begin{array}{ll}0.26 & -13.77\end{array}\right)$ & 0 & $(0.00)$ & & & \\
\hline 14 & 7 & $(10.00)$ & 418 & $(3.14)$ & 3.42 & $(1.56-7.52)$ & 4 & (17.39) & 6.49 & $(2.20$ & $-19.16)$ \\
\hline 15 & 54 & (77.14) & 12474 & (93.78) & 0.22 & $(0.13-0.39)$ & 13 & (56.52) & 0.09 & $(0.04$ & $-0.20)$ \\
\hline $\mathrm{GCS} \leq 8$ & 3 & $(4.29)$ & 79 & $(0.59)$ & 7.49 & (2.31 -24.33) & 3 & (13.04) & 25.11 & (7.31 & $-86.19)$ \\
\hline $\mathrm{GCS} \leq 12$ & 7 & (10.00) & 153 & (1.15) & 9.55 & (4.30 -21.19) & 6 & (26.09) & 30.33 & (11.80 & $-77.97)$ \\
\hline
\end{tabular}




\begin{tabular}{|c|c|c|c|c|c|c|c|c|c|c|c|c|}
\hline Scalp haematoma & 46 & $(65.71)$ & 3792 & (28.51) & 4.81 & $(2.93$ & $-7.88)$ & 14 & $(60.87)$ & 3.90 & (1.69 & $-9.02)$ \\
\hline Seizure & 10 & (14.29) & 230 & $(1.73)$ & 9.47 & (4.79 & $-18.73)$ & 4 & (17.39) & 11.96 & $(4.04$ & $-35.45)$ \\
\hline Cranial CT & 46 & $(65.71)$ & 1212 & (9.11) & 19.12 & (11.63 & $-31.43)$ & 19 & $(82.61)$ & 47.38 & (16.09 & $-139.49)$ \\
\hline Abnormal neuroimaging & 29 & (41.43) & 368 & $(2.77)$ & 24.86 & (15.28 & $-40.44)$ & 12 & $(52.17)$ & 38.34 & (16.81 & $-87.46)$ \\
\hline $\begin{array}{l}\text { Intra-cranial } \\
\text { haemorrhage/contusion }\end{array}$ & 18 & $(25.71)$ & 194 & $(1.46)$ & 23.39 & $(13.43$ & $-40.71)$ & 11 & $(47.83)$ & 61.93 & $(27.00$ & $-142.08)$ \\
\hline Skull fracture & 21 & (30.00) & 274 & (2.06) & 20.38 & (12.05 & $-34.45)$ & 5 & (21.74) & 13.21 & (4.87 & $-35.83)$ \\
\hline Neurosurgery & 2 & $(2.86)$ & 52 & (0.39) & 7.49 & (1.79 & -31.39) & 1 & $(4.35)$ & 11.58 & (1.53 & $-87.52)$ \\
\hline Intubation & 6 & $(8.57)$ & 107 & $(0.80)$ & 11.56 & $(4.90$ & $-27.27)$ & 6 & $(26.09)$ & 43.52 & $(16.83$ & $-112.53)$ \\
\hline Admission & 54 & $(77.14)$ & 2218 & (16.68) & 16.86 & (9.64 & $-29.52)$ & 18 & (78.26) & 17.99 & (6.67 & $-48.50)$ \\
\hline $\begin{array}{l}\text { Median length of stay } \\
\text { [days] (IQR) }\end{array}$ & 1 & $(1-1)$ & 3 & $(2-4)$ & & & & 4 & $(2-7)$ & & & \\
\hline PICU Admission & 8 & (11.43) & 108 & $(0.81)$ & 15.76 & (7.37 & $-33.71)$ & 7 & (30.43) & 53.44 & $(21.55$ & $-132.53)$ \\
\hline ciTBI & 14 & (20.00) & 173 & $(1.30)$ & 18.97 & (10.36 & $-34.73)$ & 10 & (43.48) & 58.37 & $(25.25$ & $-134.93)$ \\
\hline Mortality & 2 & $(2.86)$ & 12 & $(0.09)$ & 32.57 & (7.15 & $-148.30)$ & 2 & $(8.70)$ & 105.47 & (22.23 & $-500.37)$ \\
\hline
\end{tabular}


Table 3: Computed tomography (CT) scan characteristics comparing suspected $(\mathrm{n}=\mathbf{2 6})$ and confirmed $(\mathrm{n}=12)$ abusive head to non-AHT cases $(\mathbf{n}=355)$ (abnormal scan cases only).

\begin{tabular}{|c|c|c|c|c|c|c|c|c|c|c|c|c|}
\hline \multirow[b]{2}{*}{ Characteristic } & \multicolumn{2}{|c|}{ AHT suspected } & \multicolumn{2}{|c|}{ AHT not suspected } & \multirow[b]{2}{*}{ OR } & & & \multicolumn{2}{|c|}{ AHT positive } & \multicolumn{3}{|c|}{ (vs. AHT not suspected) } \\
\hline & $\mathrm{n}$ & $(\%)$ & $\mathrm{n}$ & $(\%)$ & & & $\% \mathrm{CI}$ & $\mathrm{n}$ & $(\%)$ & OR & $95 \%$ & $\%$ CI \\
\hline IN & $\angle 0$ & & 355 & & & & & 12 & & & & \\
\hline Intra-cranial haemorrhage/contusion & 17 & $(65.38)$ & 193 & $(54.37)$ & 1.59 & $(0.69$ & $-3.65)$ & 11 & $(91.67)$ & 9.23 & $(1.18$ & $-72.28)$ \\
\hline Cerebral oedema & 3 & $(11.54)$ & 46 & $(12.96)$ & 0.88 & $(0.25$ & $-3.03)$ & 3 & $(25.00)$ & 2.24 & $(0.58$ & $-8.58)$ \\
\hline Traumatic infarction & 2 & $(7.69)$ & 2 & $(0.56)$ & 14.71 & (1.98 & $-109.02)$ & 2 & (16.67) & 35.30 & $(4.51$ & $-276.48)$ \\
\hline Diffuse axonal injury & 0 & $(0.00)$ & 15 & $(4.23)$ & & & & 0 & $(0.00)$ & & & \\
\hline Shearing injury & 0 & $(0.00)$ & 2 & $(0.56)$ & & & & 0 & $(0.00)$ & & & \\
\hline Sigmoid sinus thrombosis & 1 & $(3.85)$ & 4 & (1.13) & 3.51 & $(0.38$ & $-32.60)$ & 1 & (8.33) & 7.98 & $(0.82$ & $-77.37)$ \\
\hline Midline shift or brain herniation & 5 & (19.23) & 24 & $(6.76)$ & 3.28 & (1.14 & $-9.47)$ & 2 & $(16.67)$ & 2.76 & $(0.57$ & $-13.31)$ \\
\hline Diastasis of skull & 1 & $(3.85)$ & 18 & $(5.07)$ & 0.75 & $(0.10$ & $-5.84)$ & 1 & $(8.33)$ & 1.70 & $(0.21$ & $-13.92)$ \\
\hline Pneumocephalus & 0 & $(0.00)$ & 39 & (10.99) & & & & 0 & $(0.00)$ & & & \\
\hline Skull fracture & 19 & (73.08) & 258 & (72.68) & 1.02 & $(0.42$ & $-2.50)$ & 5 & (41.67) & 0.27 & $(0.08$ & $-0.87)$ \\
\hline Depressed skull fracture & 5 & $(19.23)$ & 53 & (14.93) & 1.36 & $(0.49$ & $-3.76)$ & 2 & $(16.67)$ & 1.14 & $(0.24$ & $-5.35)$ \\
\hline Non-depressed skull fracture & 13 & $(50.00)$ & 170 & (47.89) & 1.09 & $(0.49$ & $-2.41)$ & 3 & $(25.00)$ & 0.36 & $(0.10$ & $-1.36)$ \\
\hline Basal skull fracture & 0 & $(0.00)$ & 44 & (12.39) & & & & 0 & $(0.00)$ & & & \\
\hline Unknown fracture type & 1 & (3.85) & 11 & $(3.10)$ & 1.25 & $(0.16$ & $-10.08)$ & 0 & $(0.00)$ & & & \\
\hline
\end{tabular}

This article is protected by copyright. All rights reserved. 
This article is protected by copyright. All rights reserved. 


\section{Title: Paediatric Abusive Head Trauma in the Emergency Department. A multicentre prospective cohort study}

\section{Type of manuscript: Original Article}

\section{Authors:}

Franz E Babl MD ${ }^{\mathrm{a}, \mathrm{b}, \mathrm{c}}$, Helena Pfeiffer ${ }^{\mathrm{a}, \mathrm{b}}$, Patrick Kelly MBChB ${ }^{\mathrm{d}, \mathrm{e}}$, Stuart R Dalziel PhD ${ }^{\mathrm{d}, \mathrm{e}}$, Ed Oakley MBBS $^{\mathrm{a}, \mathrm{b}, \mathrm{c}}$, Meredith L Borland MBBS ${ }^{\mathrm{f}, \mathrm{g}}$, Amit Kochar MD ${ }^{\mathrm{h}}$, Sarah Dalton BMedi, John A. Cheek MBBS $^{\mathrm{a}, \mathrm{b}, \mathrm{j}}$, Yuri Gilhotra MBBS ${ }^{\mathrm{k}, \mathrm{l}}$, Jeremy Furyk MBBS ${ }^{\mathrm{m}}$, Mark D. Lyttle MBChB ${ }^{\mathrm{b}, \mathrm{n}, \mathrm{o}}$, Silvia Bressan $\mathrm{MD}, \mathrm{PhD}^{\mathrm{b}, \mathrm{p}}$, Susan Donath MA ${ }^{\mathrm{b}, \mathrm{c}}$, Stephen J.C. Hearps PGDipBiostat ${ }^{\mathrm{b}}$, Anne Smith MBBS ${ }^{\mathrm{b}, \mathrm{q}}$, Louise Crowe $^{\mathrm{b}} \mathrm{PhD}$ on behalf of the Paediatric Research in Emergency Departments International Collaborative (PREDICT)

\section{Affiliations:}

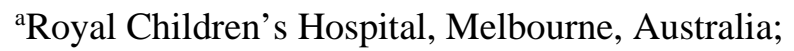

bMurdoch Children's Research Institute, Melbourne, Australia;

'Department of Paediatrics, Faculty of Medicine, Dentistry and Health Sciences, University of Melbourne, Melbourne, Australia;

'Starship Children's Health, Auckland, New Zealand;

'University of Auckland, Auckland, New Zealand;

fPrincess Margaret Hospital for Children, Perth, Australia;

gDivisions of Paediatrics and Emergency Medicine, School of Medicine, University of Western Australia, Crawley, Australia;

'Women's \& Children's Hospital, Adelaide, Australia;

'The Children's Hospital at Westmead, Sydney, Australia;

${ }^{\mathrm{j}}$ Monash Medical Centre, Melbourne, Australia;

kLady Cilento Children's Hospital, Brisbane

${ }^{\text {l} C h i l d ~ H e a l t h ~ R e s e a r c h ~ C e n t r e, ~ S c h o o l ~ o f ~ M e d i c i n e, ~ T h e ~ U n i v e r s i t y ~ o f ~ Q u e e n s l a n d, ~ B r i s b a n e, ~}$

Australia;

mThe Townsville Hospital, Townsville, Australia;

"Bristol Royal Hospital for Children, Bristol, United Kingdom;

${ }^{\circ}$ Academic Department of Emergency Care, University of the West of England, Bristol, United Kingdom;

PDepartment of Women's and Children's Health, University of Padova, Padova, Italy;

'Victorian Forensic Paediatric Medical Service, Royal Children’s Hospital, Melbourne,

Australia

\section{Corresponding Author:}

Franz E Babl,

Department of Emergency Medicine,

Royal Children's Hospital,

50 Flemington Road,

Parkville 3052,

Australia

Email: $\quad$ franz.babl@rch.org.au

Phone: $\quad+61399366748$

Fax: $\quad$ +6139345 5938

\section{FUNDING}

This article is protected by copyright. All rights reserved. 
The study was funded by grants from the National Health and Medical Research Council (project grant GNT1046727, Centre of Research Excellence for Paediatric Emergency Medicine GNT1058560), Canberra, Australia; the Murdoch Childrens Research Institute, Melbourne, Australia; the Emergency Medicine Foundation (EMPJ-11162), Brisbane, Australia; Perpetual Philanthropic Services (2012/1140), Australia; Auckland Medical Research Foundation (No. 3112011) and the A + Trust (Auckland District Health Board), Auckland, New Zealand; WA Health Targeted Research Funds 2013, Perth, Australia; the Townsville Hospital and Health Service Private Practice Research and Education Trust Fund, Townsville, Australia; and supported by the Victorian Government's Infrastructure Support Program, Melbourne, Australia. FEB's time was part funded by a grant from the Royal Children's Hospital Foundation and a Melbourne Children's Clinician Scientist Fellowship, Melbourne, Australia, and an NHMRC Practitioner Fellowship, Canberra, Australia. SRD's time was part funded by the Health Research Council of New Zealand (HRC13/556).

\section{Acknowledgement}

We would like to thank the participating families and emergency department staff at participating sites. We would like to thank research staff from the participating sites.

\section{Declaration of conflicts of interests}

None of the authors have conflicts of interests. 


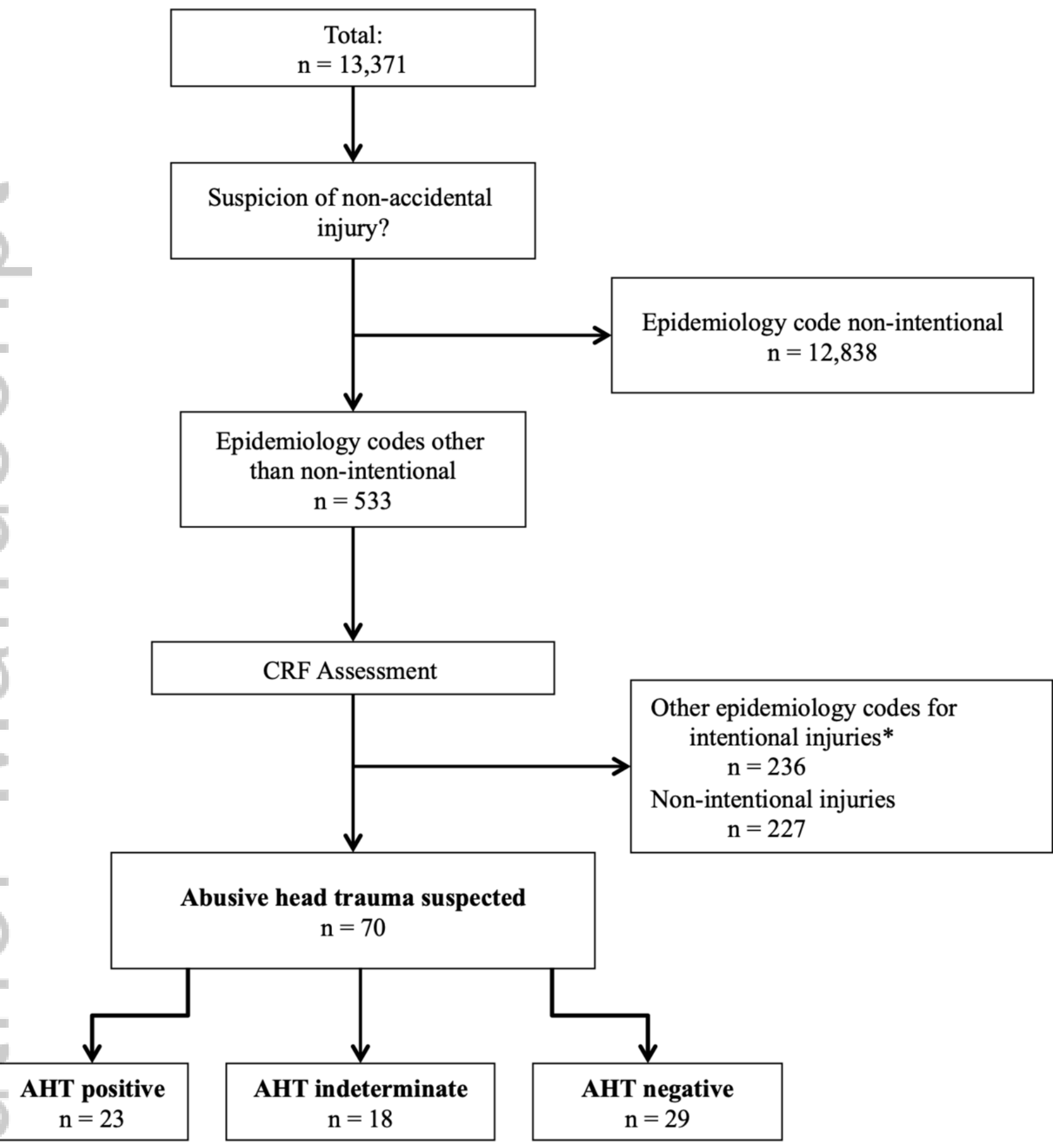

* Attack by stranger, attack by person with unknown relation to patient, intentional self-harm, legal intervention by police or security guards, other assault, attack caused by peer, attack caused by sibling, undetermined intent

$\mathrm{CRF}=$ clinical report form

JPC_14700_Figure 1 - Identification of suspected abusive head trauma R1 as submitted.tiff This article is protected by copyright. All rights reserved. 
Figure 2: Age distribution in children with suspected abusive head trauma

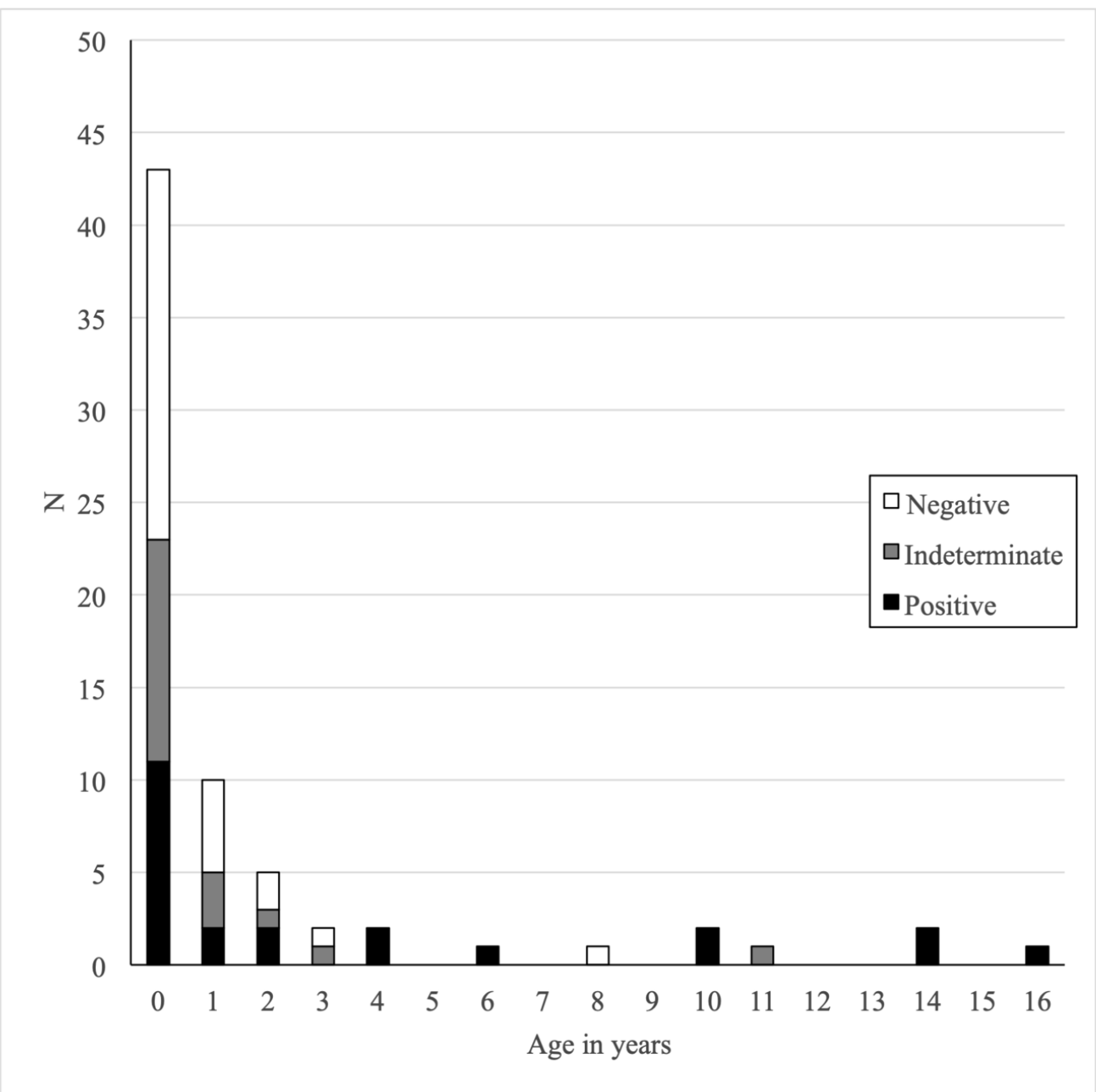

JPC_14700_Figure 2 Age Distribution 2019-11-01 as submitted.tiff

This article is protected by copyright. All rights reserved. 


\section{University Library}

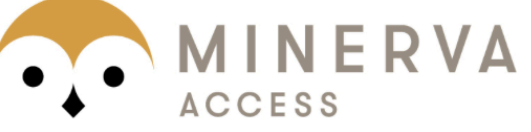

A gateway to Melbourne's research publications

Minerva Access is the Institutional Repository of The University of Melbourne

Author/s:

Babl, FE;Pfeiffer, H;Kelly, P;Dalziel, SR;Oakley, E;Borland, ML;Kochar, A;Dalton, S;Cheek, JA;Gilhotra, Y;Furyk, J;Lyttle, MD;Bressan, S;Donath, S;Hearps, SJC;Smith, A;Crowe, L

Title:

Paediatric abusive head trauma in the emergency department: A multicentre prospective cohort study

Date:

2019-12-10

Citation:

Babl, F. E., Pfeiffer, H., Kelly, P., Dalziel, S. R., Oakley, E., Borland, M. L., Kochar, A., Dalton, S., Cheek, J. A., Gilhotra, Y., Furyk, J., Lyttle, M. D., Bressan, S., Donath, S., Hearps, S. J. C., Smith, A. \& Crowe, L. (2019). Paediatric abusive head trauma in the emergency department: A multicentre prospective cohort study. JOURNAL OF PAEDIATRICS AND CHILD HEALTH, 56 (4), pp.615-621. https://doi.org/10.1111/jpc.14700.

Persistent Link:

http://hdl.handle.net/11343/286731 